\title{
Neuron Conduction Inhibition
}

National Cancer Institute

\section{Source}

National Cancer Institute. Neuron Conduction Inhibition. NCI Thesaurus. Code C40925.

Neuron Conduction Inhibition involves interference with, or restraint of, activities that propagate the transfer of the electrochemical action potential process along nerve fibers away from the cell body. 